\title{
Research on Supply Chain Simulation System Based on Internet of Things
}

\author{
Jie Zhu, Binbin Fu \\ School of Information, Beijing Wuzi University, Beijing, China \\ Email: zhujie@bwu.edu.cn, binbin6807@163.com \\ Received 10 October 2014; revised 10 November 2014; accepted 10 December 2014 \\ Copyright @ 2015 by authors and Scientific Research Publishing Inc. \\ This work is licensed under the Creative Commons Attribution International License (CC BY). \\ http://creativecommons.org/licenses/by/4.0/ \\ (c) (i) Open Access
}

\begin{abstract}
As one of the top ten core industries in China, Internet of things, has gradually changed our life, by influencing enterprise production, storage and transportation, express, supermarket shopping, etc. By using Internet of things technology in the supply chain, enterprise can optimize the structure and process of supply chain management system, improve the information transmission speed and things matching accuracy, and improve the operation mode of supply chain. The paper constructs a supply chain simulation system based on Internet of things. Firstly we analyze the process of the simulation system, and then introduce key techniques of simulation platform and main functions of the system. The work provides a basic platform for follow-up research of Internet of things, and a training system for students.
\end{abstract}

\section{Keywords}

Supply Chain System, System Simulation, IOT Technology

\section{Introduction}

Today IOT technology has gradually been known, but its use is not so optimistic. Now IOT has just been partly used in supply chains GPS (Global Position System) technology application in the transportation process, ZigBee and sensor in cold chain or warehouse. However RFID (Radio Frequency Identification), the core technology of IOT, has not been widely applied in the supply chain [1] [2]. Therefore, this paper constructs a supply chain simulation system based on IOT technology, which integrates RFID technology, GPS technology, GIS technology, ZigBee technology, sensor technology [3], etc. First we analyze the overall architecture of the system, and then introduce the key technology of the system implementation and the function and process of the system, which provide a basic platform for the subsequent IOT study. 


\section{The Process Design of Simulation System}

Based on Internet of things and wireless network technology, the system realizes the trace of product life cycleand visual management. Driven by product sales, data sharing as the premise and supported by the Internet of things technology, the whole system is closed-loop supply chain system for simulation the entire operation including production, distribution centers, transportation enterprise and supermarket [4].

First, the system simulates the production factories. When factory receives the production and processing of orders from the distribution center, production plan is made. In production, there are three process including initial product labeling, product putting in storage, processing. Production finished, with a unique identification of the product transport to the distribution center, there are six processes of distribution center management including storage of goods, inventory management, out of storage, packing container labeling, pallet labeling, ready to transport. Second, after the distribution center receive orders from the supermarket that generated stock out and distribution order, then shipped out the production. Thirdly, the production in transit, the vehicle terminal in road send information intransit to data center for distribution center and supermarket real-time view. When the goods arrived to the supermarket into the supermarket background management including the storage of goods, inventory management, and the goods on the shelves. The background to receive replenishment orders from the foreground, it generated stock out list according to replenishment orders. In the supermarket foreground system customers choose and buy goods to use smart shopping cart. Intelligent shelves system can be updated in real time goods inventory information, when quantity of product was reduced to a certain value, system issued a warning. Management place replenishment orders according to inventory and sales and inform the background replenishment as shown in Figure 1.

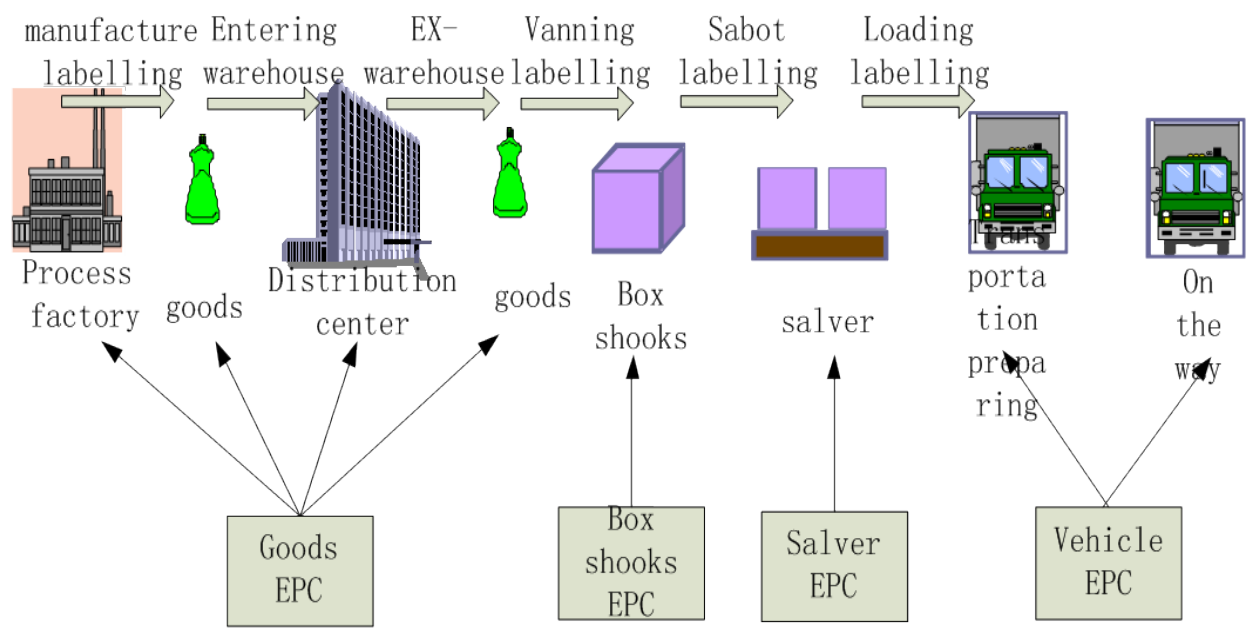

(a)

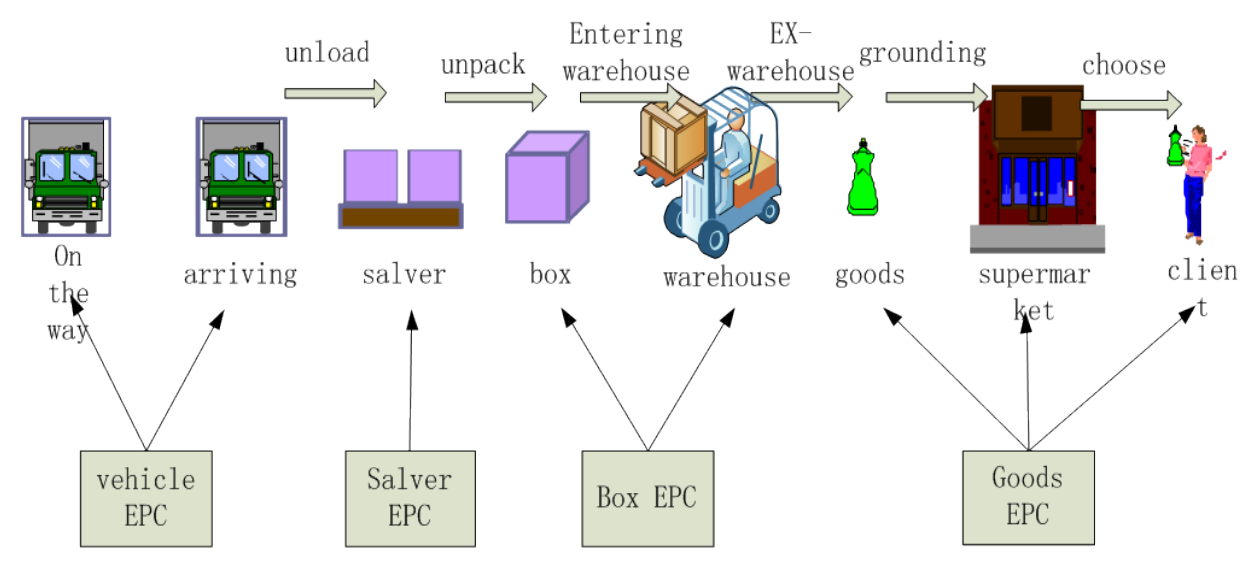

(b)

Figure 1. Business flow chart (a); Business flow chart (b). 


\section{The Key Techniques in the Simulation System}

\subsection{Production Environment Monitoring Subsystem}

Intelligent production environment monitoring system to use all kinds of sensors are gathering all the environmental information on production processes like temperature, humidity, pressure and degree of vibration information that will pushed to PC to store by ZigBee transmission network. ZigBee system include: embedded sensor nodes, RFID reader, PC, production line equipment, etc.

Embedded ZigBee node equipment of all kinds of sensors installed on each process equipment real-time monitor environmental information of each production process, such as temperature and humidity information, production status information, degree of vibration, etc. When items to be produced into a process, RFID antenna deployed in the process will read the product ID in the location and then send product ID to PC. When production process is finished, It store in the database to bind the temperature and humidity environmental information in the process of producing and the only sign of products completion the product production environment monitoring to ensure the safety of the product production and subsequent traceability requirements.

\subsection{RFID Intelligence in-out Warehouse Management Subsystem}

RFID intelligence in-out warehouse management subsystem, its implementation intentions and logic as well as the traditional storage member manual input, is combined with the RFID tag, RFID reader, automatic control, computer, network and other advanced technology and equipment to complete goods in-out warehouse management. Purpose is to provide more convenient and flexible, more efficient, more powerful means of warehouse management.

The RFID in-out warehouse system is mainly divided into three parts, the sensing module: RFID tags binding on the packing of the goods. Information reading module: HF or UHF (Ultra High Frequency) RFID reader. Control module, PC with warehouse management system. Binding product packaging to RFID tags before cargo warehousing, when the goods is going into the warehouse, RFID reader and RFID tag on packaging on radio frequency signal exchange information with control system through the network, the control system assigned EPC (Electronic Product Code) number to each goods, a unique identity to ensure the goods traceability within the warehouse. All the process of warehouse real-time information transmitted by RFID tag and reader and the control system to make goods visual management.

\subsection{Intelligent Transportation Monitoring Subsystem}

1) Vehicle location tracking system

Intelligent transportation monitoring system mainly involves in the GPS technology and GIS technology, the basic principle of GPS positioning is based on instantaneous position of the satellite high speed movement known as initial data, using the method of spatial distance resection to determine the test location. And GIS (Geographic Information System) is based on geographical spatial database support of computer hardware and software comprehensive analysis geographic data with spatial connotation to provide management and decision-making and other required information.

GPS and GIS to a certain extent is inseparable. Only the existence of GIS, user can see intuitive position with avariety of geographical information in PC; only the existence of the GPS, intelligent transport system can obtain the user's location information based on mobile phone positioning, and transmit to the receiving server through the GPRS data transmission mode. Background management system access to GPS data and shows by GIS. Car-carried GPS terminal determine and sent space coordinate information of the vehicle to the WEB server. WEBGIS system accessed WEB server will get vehicle coordinates information of geographical environment, background management system through the location data can be corresponding monitoring and management. As shown in Figure 2.

2) Vehicle condition monitoring systems

Condition monitoring system for vehicles in road application of the wireless sensor technology. There are various types of sensors inside the car and tires such as temperature and humidity sensor, tire pressure sensor transfer vehicle state information to the car terminal through the ZigBee technology, using the GPRS technology transfer vehicle environmental information state data to the network server to realize real-time monitoring of the state of the vehicle. As shown in Figure 3. 


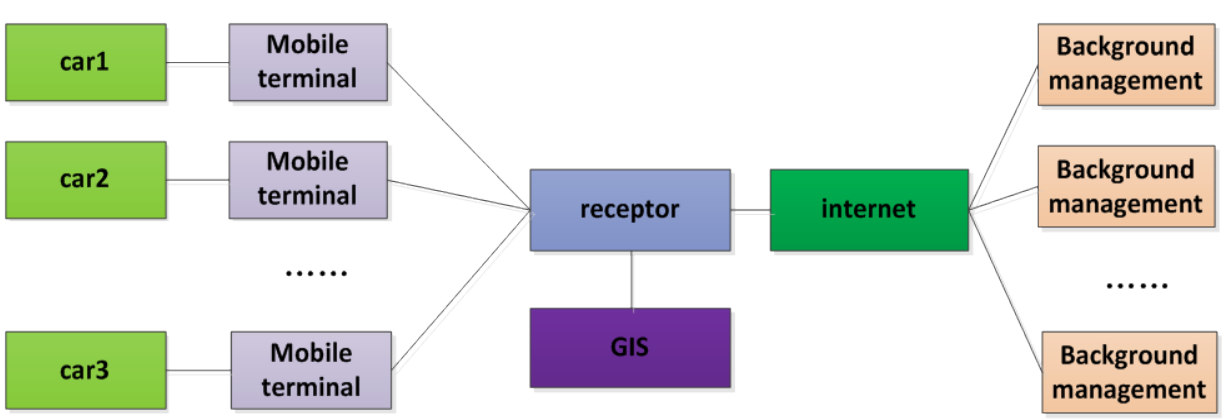

Figure 2. Structure diagram of smart transportation positioning system.

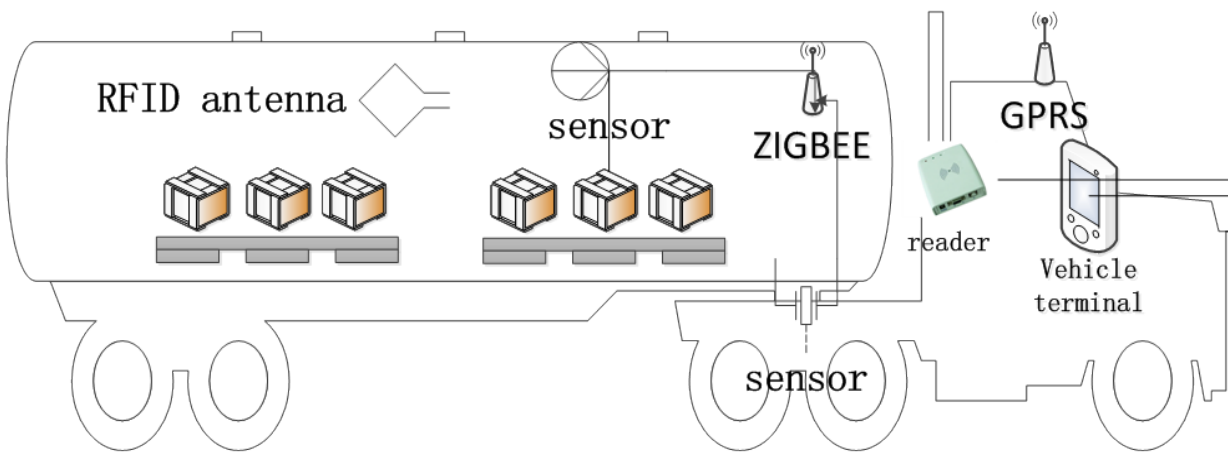

truck

\section{Figure 3. Vehicle condition monitoring system.}

Car terminal not only accept the vehicle location information data, vehicle environmental information data, also identify drivers and EPC code of product in vehicles, and send GPS data, environmental data, EPC data, personnel information to web server by GPRS (General Packet Radio Service), which not only achieve monitoring the position of the vehicle and car environment, also provide traceability of on-board goods and management according to vehicle EPC.

\subsection{Intelligent Goods Shelves Subsystem}

Smart shelves system can be achieved real-time monitoring goods information in shelves and update information of on or off shelves. Its design adds a reader antenna to each cargo grid of conventional shelf and every eight antenna connected to reader through an antenna adapter. According to the placing of the goods required, antenna be put on bottom and top of grids. By using a reader connected to the eight antenna solution reduce the number of reader device, thus reducing the cost of deploying. Main controller inspect goods number placed in, whether goods in or out the shelves by controlling the working state of the antenna. It will inspection of goods and inventory management functions. Smart shelves equipment should have the following functions:

1) Smart shelves terminal can show the name, properties, quantity of goods of each position on the warehouse shelves;

2) Smart shelves terminal automatic perception goods state whether in or out shelves;

3) Smart shelves terminal send working information to the warehouse management server;

4) Smart shelves LED can show Chinese characters, English letters, digits or graph and display width is four Chinese characters.

\subsection{Smart Shopping Cart Subsystem}

The supermarket smart shopping carts act as assistants to assist the user to choose goods, its design is based on the existing shopping cart increase IPAD and RFID reader information interaction with server through wireless network. 
The key part of Smart shopping cart is that IPAD embedded into shopping cart and connected to the RFID reader, IPAD communicate with the data center and smart shelves using wireless network .In use process, users put registered membership card into the card read, then reader read the card information displayed in IPAD, while shopping guide program starts. Smart shopping cart interact frequently with smart shelves and data center to ensure information instantaneity. Smart shopping cart main functions are as follows:

1) View: through information query in the database, user can get the details of the goods, including the production information, shipping information, raw material supply information, at the same time can also see the commodity discounted information, etc.

2) Goods location map: through RFID reader of smart shopping car, user can get the position information of goods and quickly find the desired items through navigation system.

3) Quick settlement: through RFID reader of smart shopping car, user can add goods chose to cart (including physical and virtual cart) and confirm the chose and buy goods after pass door RFID reader. then complete the quick settlement.

\section{The Function Design of Simulation System}

\subsection{Production Management}

Platform can simulate the whole process of production enterprises and make production smart management function through the application of IOT technology. Production management module include functions of product labeling, product processing and finished product checking; The production plan management module draw up the plan according to receive orders from system; Order management module includes viewing order information and order processing; Production management module of the system can manager product categories of system production; Warehouse management includes inventory management and out of storage management function, the former monitoring products in stock information, the latter shipment handling according to processed orders; Customer management module maintain information of customer; System settings consists of a serial port settings and information settings and set up the software running parameters and so on.

\subsection{Intelligent Distribution}

In simulated distribution link, distribution center according to the supermarket order generate stock out and distribution list, the former is given Warehouse and later is given transport sector. After out of storage the system automatically updated inventory information; After the completion of out of storage, the goods is packing after passing sorting operations; In the packing, a certain number of finished goods package boxes, and labeling in each box. In the transport links, box as a unit will be managed. Transport department is shipment preparation after getting distribution list, first it distribute vehicles, drivers for distribution list and improve the distribution list information; At the same time, before loading the number of box is carried in a pallet, RFID electronic label is affixed to each pallet and pallet ID associated with the vehicle ID. Form of the only vehicles and the only driver with the corresponding pallet are monitored eventually.

Smart shelves in the warehouse will real-time monitor the inventory information updated, if the inventory number is less than a certain range, distribution center generate produce replenishment order to inform the production enterprise for production and processing activities. Smart shelves will realize automatic quick inventory physical count. And inform the EPCIS (EPC Information Services) server out of storage, warehousing and inventory of commodity information. This system complete intelligent inventory management function by adopts the smart shelves.

\subsection{Intelligent Transportation}

Platform can simulate the whole process of transportation and realize intelligent transportation management functions through the application of IOT technology. In road link, the drivers of transportation get distribution list and complete the preparation activities to automatic complete the vehicle and the driver matching through the RFID technology, and start a series of executable program of vehicle like opening the GPS system automatically, show distribution tasks and route, etc. In road, vehicle real-time send in road information to the data center including vehicle speed and position information, etc. When abnormal situation have happen, such as speeding, deviating from the transport routes, system gives an alarm, starts vehicle anti-theft system, and report vehicle position information to the data center server. 


\subsection{Supermarket Foreground Sales}

Users, in the supermarket (shopping mall) using smart shopping cart for purchase, will place membership card that need to be registered and recharged early to swipe area, the system will read out the customer information. At the same time it recommend discounts commodity to customers based on the user's consumption records. When the user needs to choose and buy a commodity, it is able to find the location of the commodity according to the product category, intelligent touch screen can query the inventory and specific location information of commodity of system via WIFI network.

When the customers choose and buy some commodities, they can view commodity information in intelligent touch screen by RFID module in smart shopping cart read commodity EPC code of RFID tag, when users click on the confirm button, commodities will be added to the shopping cart system.

Customer push the shopping cart to settlement, system will read the goods information of customers choose through door type RFID reader, if the information of commodity read with in shopping cart are no difference, then confirm purchase and payment. Transaction is over.

\subsection{Supermarket Background Management}

Supermarket background system mainly includes smart supermarket background management system and intelligent materials monitor system.

1) Smart supermarket background management system, which can realize user management, commodity classification management, commodity in library management, sales management, after-sales service, order management and system management functions.

2) Intelligent materials monitor system, mainly including goods monitoring, shortage of monitoring, materials parameter setting, system parameter setting, etc. Materials monitoring: intelligent terminal equipment that can show name, properties, quantity of the goods on each position of warehouse shelves. Shortage monitoring: smart shelves terminal equipment send the working information to warehouse management server, which you can know whether the goods out of stock. Material parameters Settings: setup type, product name, safety stock, color, logo etc. System parameter Settings: including set the listener port, check interval time of safety stock, RFID reader, data transmission format. Help: show the version number of the system and operation manual.

\section{Conclusion}

This paper built a supply chain simulation platform system based on IOT technology, analyzed the application of key technology in the system, and designed smart shelves subsystem, smart shopping cart subsystem and so on. The operation process is simulated according to the particularity of the supply chain enterprise [5]. The system can provide a full range of search service for customers through the WEB service, and realize the visualization management of the whole process of mobile commerce so the user can trace the whole process of goods for safety and achieve more efficient supply chain management.

\section{Acknowledgements}

This research was supported by the Beijing key intelligent logistics system laboratory.

\section{References}

[1] Wang, F.Q. (2012) Research New Type of Supply Chain Management Model Based on the Technology of Internet of Things-With Radio Frequency Identification (RFID) Technology as an Example.

[2] Shen, S.B., Fang, Q.L. and Zong, P. (2009) Research of Internet of Things and related technology. Journal of Nanjing University of Posts and Telecommunications (Natural Science), 6, 1-11.

[3] Wang, B.Y. (2009) Summary of IOT Technology Research. Journal of Electronic Measurement and Instrument, 12, 1-7.

[4] Lin, G. (2012) Research on Complex Event of Supply Chain Decision Support Based on Internet of Things.

[5] Han, Y. and Chai, Y.T. (2011) The Architecture Reference of Flexible Supply Chain Simulation System. Journal of System Simulation, 6, 1270-1278. 
Scientific Research Publishing (SCIRP) is one of the largest Open Access journal publishers. It is currently publishing more than 200 open access, online, peer-reviewed journals covering a wide range of academic disciplines. SCIRP serves the worldwide academic communities and contributes to the progress and application of science with its publication.

Other selected journals from SCIRP are listed as below. Submit your manuscript to us via either submit@scirp.org or Online Submission Portal.
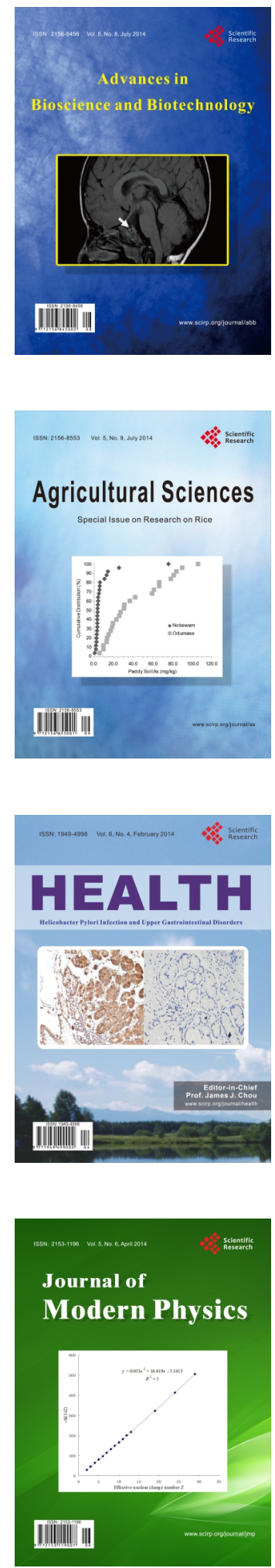
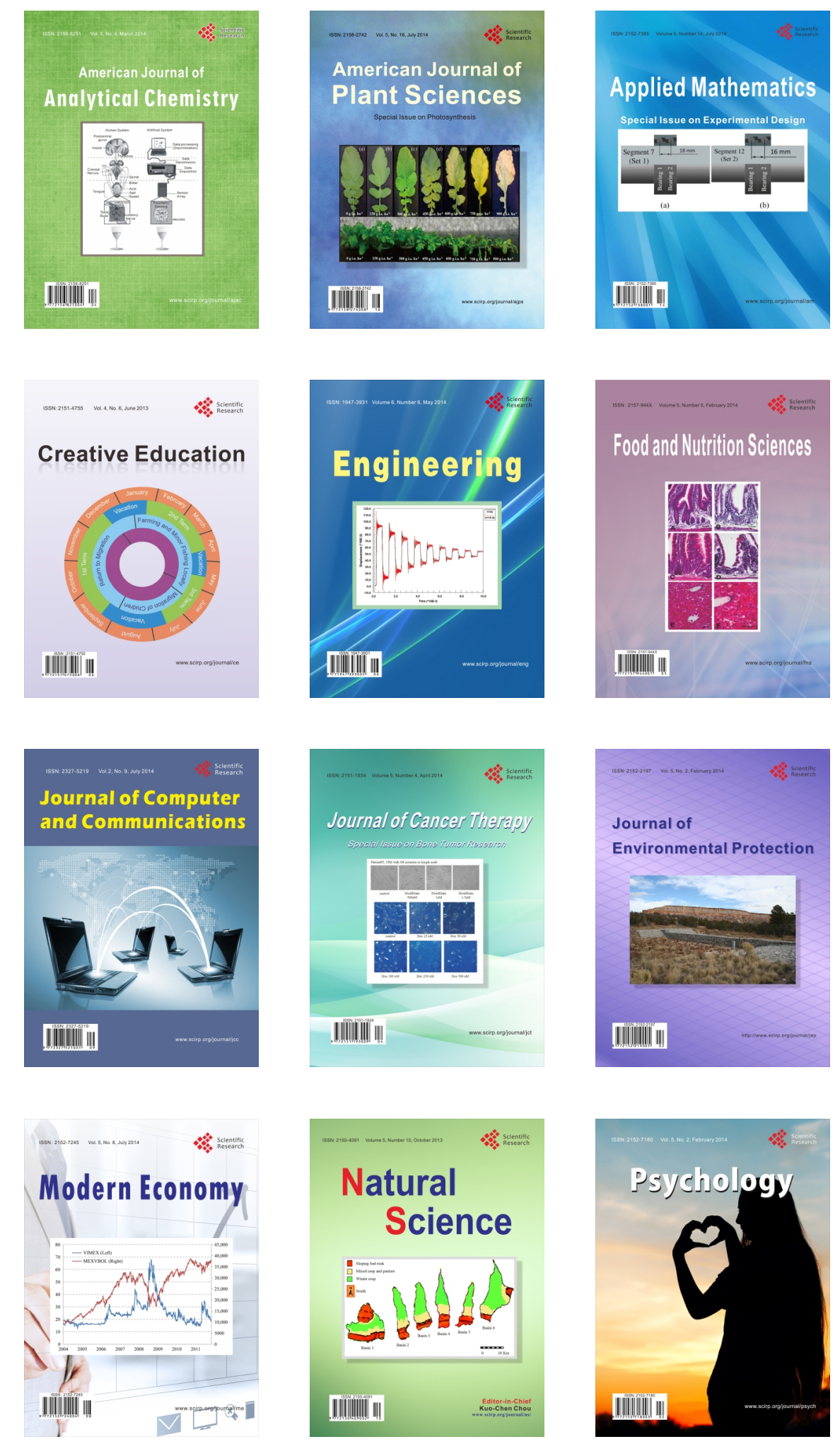